\title{
Thirlwall's law is not a tautology, but some empirical tests of it nearly are
}

\author{
Robert A. Blecker* \\ Professor of Economics, American University, Washington, DC, USA
}

This article examines the charge that Thirlwall's law is a theoretical tautology. It shows that a certain approach to empirical testing of that law can sometimes - under conditions analysed here - result in econometric estimates that reflect an approximate identity or 'near-tautology'. Nevertheless, other methods of empirically testing the law are not subject to the near-tautology critique, and hence the theory itself is not a tautology. Econometric estimates for the US and Mexico reveal that the near-tautology critique applies to data for the former but not the latter; the difference in these results is explained by exactly the reasons discussed here. The article offers an alternative interpretation of Thirlwall's law as implying a benchmark for analysing whether national income, rather than relative prices, is the main adjusting factor in response to current-account imbalances in the long run.

Keywords: Thirlwall's law, balance-of-payments-constrained growth, income elasticities, near-tautology critique, income vs price adjustment

JEL codes: $E 12, F 32, F 43, O 47$

\section{INTRODUCTION}

There is a famous saying that 'there is no such thing as bad publicity'. From this point of view, the tremendous amount of attention that the model of balance-of-paymentsconstrained growth (BPCG), originally developed by Thirlwall (1979), has received over the past four decades is a true and lasting tribute to the progenitors of that theory, even if some of the attention has been critical. The original Thirlwall model has served as the foundation for numerous theoretical extensions and empirical applications, as summarized in McCombie and Thirlwall (1994; 2004), McCombie (2011), Thirlwall (2011) and Blecker and Setterfield (2019), among others. This approach has also received its share of criticism, as is common for all theoretical models in economics. Various alternatives to the original Thirlwall framework have been proposed, all of which are also testaments to its importance and influence. In the same spirit, I suppose I should be grateful that McCombie (2019) and Thirlwall (2019) have responded, albeit rather negatively, to some points I made in my survey of debates about the BPCG model in Blecker (2016). ${ }^{1}$

* Email: blecker@american.edu. The author would like to thank Carlos Ibarra, Arslan Razmi, Mark Setterfield and two anonymous referees of this journal for helpful comments on earlier drafts. The author alone is responsible for the views expressed here and any remaining errors.

1. I was invited to write that survey by the editors of the European Journal of Economics and Economic Policy: Intervention (EJEEP), in order to review and comment on recent controversies about the BPCG model, including some that had been published in Spanish and were not easily accessible to English-language readers. 
However, I cannot take credit for (and indeed, I did not state) what McCombie refers to as 'Blecker's argument'. What he seems to be referring to is my account of a critique that was originally stated by none other than McCombie (1981) himself, before he later abandoned it, and which was more recently revived by others (Clavijo and Ros 2015; Razmi 2016). This is the argument that empirical tests that compare the equilibrium growth rate predicted by Thirlwall's model with actual, historical average growth rates are testing a near-tautology (or near-identity). To clarify, this is a claim that a certain method of empirically testing the theory is close to testing a tautology, but it is not necessarily a claim that the BPCG model or its theoretical solution (often called 'Thirlwall's law') is a tautology. As long as there are other empirical methodologies for testing the validity of this theory - and I will argue below that there are - then the law itself is not a tautology. Moreover, as I will show below, this critique is only valid under certain conditions. Thus, when McCombie (2019, p. 431) refers to 'Blecker's argument that the law is merely a tautology', this is simply inaccurate; I made no such claim, and I do not believe that.

Indeed, I think I make a very poor candidate for being hostile to the BPCG model or Thirlwall's law. I have published numerous applications and/or extensions of this modelling framework, including Blecker (1992; 1998; 2002; 2013), Blecker and Ibarra (2013), and Ibarra and Blecker (2016). Blecker (1998) was included in a volume edited by McCombie and Thirlwall (2004), but except for my 2016 survey article, none of my more recent papers utilizing this approach is cited by McCombie (2019) or Thirlwall (2019). Furthermore, I have taught the BPCG model (very favourably) in my graduate courses at American University for several decades, and I have also lectured on it (quite sympathetically) at numerous Post-Keynesian graduate summer schools (most recently in 2019 in Berlin). I would not have devoted a considerable part of my career to working on this approach and teaching it if I did not find it valuable or if I believed it to be merely stating a tautology (see my interview in Blecker 2018).

In a graduate-level text I have recently co-authored (Blecker and Setterfield 2019), the BPCG approach is the only branch of heterodox growth theory that is treated in two separate chapters; all other approaches are covered in only a single chapter or just a part of a chapter. We devoted two chapters to this approach precisely because we thought it was so significant and the literature on it is so vast that we could not do it justice in one chapter. The book concludes with a (very favourable) presentation of an article co-authored by McCombie (Ribeiro et al. 2017a), which neatly synthesizes a Thirlwallian approach to the long run with a more Neo-Kaleckian framework for the short and medium run - an article we characterize as providing 'a grand synthesis' (Blecker and Setterfield 2019, pp. 502-510). All of this should make it clear that the BPCG approach is one I value and respect.

The reason why I believe this model is so powerful relates to its central message about how the balance-of-payments constraint in open economies imposes limits on the growth of domestic demand and, in demand-driven systems, thus constrains the long-term growth of output. As McCombie and Thirlwall (2004, introduction, p. 7) have written, the BPCG model - along with its earlier antecedent, the Harrod (1933) trade multiplier is based on the belief that 'income adjustment as opposed to relative price adjustment' is 'the mechanism by which a country's balance of payments is brought back into equilibrium'. Applied to the long run, this principle constitutes the core idea behind Thirlwall's law. If that is true, then the law can be tested by directly estimating to what degree income or prices do the adjusting to balance-of-payments disequilibria in 
the long run - and such tests (discussed in Section 4 below) are not subject to the neartautology critique. ${ }^{2}$

Before proceeding further, I would like to clarify a few points. When I set out to write the survey that became Blecker (2016) - at which time I had already read earlier drafts of what was later published as Razmi (2016) - I took an open mind on the debate about the near-tautology critique. I sought only to explain the arguments on both sides of this issue (along with other controversies about the BPCG model). However, since writing that survey and in the course of thinking about the criticisms by McCombie and Thirlwall of what I wrote then, I have further developed and refined my own understanding of the subject - and McCombie's arguments in particular have helped me to clarify the issues at stake. Although what is presented here is an inevitably personal account, I will try to focus on the merits of the arguments. I should also acknowledge that my views may not be identical to those of previous advocates of the near-tautology argument. Some of them may have believed that Thirlwall's law is a theoretical tautology or criticized it on other theoretical grounds. ${ }^{3}$ But this article focuses exclusively on trying to clarify the debate about whether certain empirical tests of Thirlwall's law involve a near tautology.

The rest of this article proceeds as follows. Section 2 clarifies the basis for the neartautology critique in relation to the previous literature and identifies the conditions under which it does or does not apply. Section 3 presents econometric estimates testing whether the conventional empirical methodology yields nearly tautological empirical results for two major countries, the US and Mexico. Consistent with the analysis from Section 2, the results show that the near-tautology argument holds in the US case, where the data satisfy those necessary conditions, but not in the Mexican case, where the data do not satisfy those conditions. Section 4 discusses alternative empirical approaches that constitute more powerful tests of the BPCG model. These approaches involve testing whether national income or the relative price is the adjusting variable

2. The BPCG model rests on what used to be called the 'elasticities approach' to the balance of payments, in which relative incomes and prices drive trade flows and these flows determine the current-account balance. Many economists have shifted to a view of the balance of payments in which the current-account deficit is instead driven by the capital-account (financial asset transactions) balance, which - depending on the model - may be determined by factors such as intertemporal optimization or expected interest-rate differentials. The BPCG model has been extended to include capital flows, for example by Thirlwall and Hussain (1982) and Moreno-Brid (1998-1999), but in these models net capital inflows are either exogenous or adjust to maintain an exogenously given 'sustainable' ratio of the current-account deficit (or foreign debt) to GDP. More attention to the financial side of the balance of payments and how it interacts with exchange rates, trade flows and the current account is clearly an area that needs more attention in the BPCG framework. For a recent study of the determinants of current-account imbalances using a Post-Keynesian (but not BPCG) approach, see Guschanski and Stockhammer (2020).

3. Of course, some economists may regard the BPCG model and the Thirlwall's law solution as theoretical tautologies, but I am not among them. Some critics have made other, theoretical criticisms of that approach, which (as I understand them) are distinct from the near-tautology argument. For example, Clavijo and Ros (2015) argue that for an economy that is dependent on imports of capital goods, achievement of the Thirlwall's law growth rate requires endogenous adjustment of the terms of trade (which inversely reflect the world relative price of capital goods). Razmi (2016) argues that the standard Thirlwall model is not applicable to small, open economies, which face infinitely elastic export demand curves at given world prices, while their equilibrium quantities of exports are determined by domestic supply constraints (capital stocks). These issues are beyond the scope of the present article, but are discussed in Blecker and Setterfield (2019, pp. 494-502), while critiques of Clavijo and Ros's alternative model can be found in Pérez Caldentey (2015) and Vernengo (2015). 
that maintains current-account balance in the long run, and they imply that the Thirlwall's law growth rate should be considered more as a benchmark for that adjustment process rather than a 'prediction' of actual average growth rates. Section 5 concludes with a discussion of what I think should be the main issues going forward - and where, hopefully, Professors McCombie and Thirlwall and I can find ample room for agreement and more fruitful areas for debate.

\section{THE NEAR-TAUTOLOGY ARGUMENT}

Thirlwall curtly dismisses the near-tautology argument in the following passage (where $g$ is the growth rate of income, a $b$ subscript indicates the balance-of-payments-constrained growth rate, $x$ is the growth rate of exports, and $\pi$ is the income elasticity of import demand):

One misconception that needs to be buried for good is that the dynamic Harrod trade multiplier [Thirlwall's law] result that $g_{b}=x / \pi$ is based on an identity, or is a tautology, because in the long run the growth of exports is bound to equal the growth of imports. This canard was originally raised by McCombie (1981), but he soon changed his mind as a result of my response to him (Thirlwall 1981). The misconception has had an unfortunate reincarnation in the works of Blecker (2016) and Razmi (2016), among others. The result would reflect an identity if the income elasticity of demand for imports $(\pi)$ is measured as $\mathrm{m} / \mathrm{g}$, where $m$ is the growth of imports and $g$ is actual output growth, but it is not. The income elasticity of demand for imports in all the empirical work I know (including the original estimates of $\pi$ that I used in the 1979 paper, taken from Houthakker and Magee 1969) is estimated econometrically, controlling for changes in the real exchange rate, or the real terms of trade. (Thirlwall 2019, pp. 557-558)

Aside from its dismissive tone, this statement misrepresents the near-tautology argument, making it seem like a simple fallacy. No one in the contemporary literature (at least, no one I have read or cited) has claimed that the income elasticity $\pi$ is 'measured' as $\mathrm{m} / \mathrm{g}$ (using Thirlwall's notation; I will introduce my own notation below). For example, Clavijo and Ros (2015, p. 25) acknowledge that 'the income elasticity of demand for imports is not calculated in this form [as a ratio of actual average growth rates], but rather through econometric estimations', ${ }^{4}$ while Razmi (2016) expressly discusses such econometric estimates. Instead, the critics' claim is precisely that the econometrically estimated income elasticity will (under certain conditions) turn out to be approximately the same as $\mathrm{m} / \mathrm{g}$; hence, these empirical tests are alleged to reflect a near-identity or near-tautology. Thus, the critique claims that certain empirical tests of Thirlwall's law have low power to reject the null hypothesis that Thirlwall's law holds; it does not necessarily assert that the theoretical solution of Thirlwall's model itself is a tautology. This is a vital distinction, which both McCombie (2019) and Thirlwall (2019) elide.

This distinction should have been clear from what I wrote in my 2016 survey. Referring to the Thirlwall's law solution as the balance-of-payments (BP) equilibrium growth rate, ${ }^{5}$ I stated the following:

Most empirical tests of Thirlwall's law have focused on determining whether actual, long-run average growth rates are close to the BP-equilibrium growth rates predicted by the BPCG model. Using a wide variety of econometric methodologies (the details of which need not

4. Translated by the author (all translations from Spanish are by the author).

5. This mirrors the terminology originally used by Thirlwall (1979, pp. 45-46), who called his model's solution 'the balance of payments equilibrium growth rate'. 
detain us here), numerous empirical studies have confirmed that actual average growth rates are close to BP-equilibrium growth rates for the vast majority of countries and (long-run) time periods considered (see Thirlwall 2011 for a survey and references). However, as argued long ago by McCombie (1981) and more recently by Clavijo/Ros (2015) and Razmi ([2016]), it can be claimed that such tests of Thirlwall's law are testing a near-identity that is likely to be satisfied for almost any country regardless of whether its growth is BP-constrained in the sense of Thirlwall or not. (Blecker 2016, pp. 276-277, emphasis added)

In case that statement was not clear enough, I then made the point even more sharply:

It is important to recall, however, that the 'near-identity' critique is only a criticism of certain types of empirical tests of Thirlwall's law. This critique suggests that statistical tests of equality between the actual and BP-equilibrium growth rates have weak power to reject the null hypothesis that these growth rates are equal. This critique does not necessarily disprove Thirlwall's law, however; it simply implies that other, more powerful statistical tests are required to validate it. These more powerful tests are found in the (relatively fewer) studies that have more directly tested what Pérez [Caldentey, 2015] calls the essence of the law: whether BP equilibrium is achieved through adjustments in national incomes rather than relative prices. (Blecker 2016, p. 279, emphasis added)

Neither McCombie (2019) nor Thirlwall (2019) cites these passages, which clearly show that I did not advocate the views they incorrectly attribute to me.

I will return to discuss the 'more powerful statistical tests' in Section 4, below, but here I will focus on what I have come to view as the core of the near-tautology argument. As is well known (so I will not bother to provide a derivation here), ${ }^{6}$ the two versions of Thirlwall's law are (in the terminology of Perraton 2003, but in my own notation):

$$
\begin{gathered}
\text { Weak version: } \quad g_{Y}^{B}=\frac{g_{X}}{\eta_{M}} \\
\text { Strong version: } \quad g_{Y}^{B}=\frac{\eta_{X} g_{Y}^{f}}{\eta_{M}},
\end{gathered}
$$

where $g_{A}$ is the growth rate of any variable $A$, assumed to be measured by the difference in natural logarithms, ${ }^{7} Y$ is national income (output), $X$ is the real quantity of exports, $M$ is the real quantity of imports, $\eta_{i}$ is the income elasticity of demand for good $i(i=X, M)$, a superscript $f$ indicates a foreign variable (thus, $g_{Y}^{f}$ is the growth rate of foreign income), ${ }^{8}$ and $g_{Y}^{B}$ signifies the BP-equilibrium (Thirlwall's law) growth

6. See, for example, McCombie and Thirlwall (1994) and Blecker and Setterfield (2019), among many others.

7. Thus, for any variable $A, g_{A}=d \ln A / d t$, where $t$ is time. I use the $g_{A}$ notation for growth rates instead of the commonly used 'hat' notation (a circumflex over the variable) to avoid confusion with estimated regression coefficients and fitted values, which (as is also traditional) will be indicated using hats (circumflexes) below.

8. This standard formulation of Thirlwall's law thus makes the simplifying assumption of a single 'home' country trading with one undifferentiated 'foreign' country or the rest of the world, when in reality individual exporting countries often compete with each other in 'third country' markets. Blecker (2002) extended the BPCG framework to a multilateral model in which multiple exporting countries compete in the same foreign markets, while Blecker and Razmi $(2008 ; 2010)$ conducted empirical tests of the 'fallacy of composition' hypothesis in which such competition limits the ability of individual developing countries to pursue simultaneous export-led growth. 
rate of domestic output. To obtain an estimate of $g_{Y}^{B}$, a researcher typically estimates the income elasticities $\eta_{X}$ and $\eta_{M}$ and then combines them with observed data on the sample mean of $g_{Y}^{f}$ using equation (2), or simply combines an estimate of $\eta_{M}$ with the observed sample mean of $g_{X}$ using (1).

One key part of the near-tautology argument is the assertion that, in a long-run data sample, the econometrically estimated income elasticities $\widehat{\eta}_{X}$ and $\widehat{\eta}_{M}$ are likely to approximate the income elasticities calculated from descriptive data, where the latter are the ratios of the average growth rates of trade volumes (exports or imports) and the corresponding national incomes (foreign or domestic):

$$
\begin{gathered}
\hat{\eta}_{X} \approx \frac{\bar{g}_{X}}{\bar{g}_{Y}^{f}} \equiv \bar{\eta}_{X} \\
\hat{\eta}_{M} \approx \frac{\bar{g}_{M}}{\bar{g}_{Y}} \equiv \bar{\eta}_{M},
\end{gathered}
$$

where a bar over a growth rate indicates its sample mean and $\bar{\eta}_{X}$ and $\bar{\eta}_{M}$ are what McCombie (2019) calls the 'calculated elasticities'. If this is the case, then Thirlwall's law (by either definition, (1) or (2)) will appear to be (approximately) satisfied, that is, $g_{Y} \approx g_{Y}^{B}$, as long as (in addition) $\bar{g}_{X} \approx \bar{g}_{M}$, or, in other words, if the volumes of exports and imports grow at similar rates in the long run. Given that Thirlwall's law is supposed to be a long-run proposition, and given that $\bar{g}_{X} \approx \bar{g}_{M}$ is more likely to hold, the longer the time period considered (since trade balances cannot grow indefinitely larger or smaller, which is a key assumption of Thirlwall's), the argument is that the law will often appear to be satisfied in long-run data sets.

As stated here, the near-tautology argument thus requires two separate and independent conditions: first, that the econometrically estimated income elasticities closely approximate the income elasticities calculated from sample mean growth rates; and second, that the volumes of exports and imports grow at similar rates in the long run. The previous literature has not been as clear on this distinction as it could have been, however, sometimes making it appear that the second condition is sufficient for the near-tautology to hold or that the second implies the first (which may perhaps be the source for some of McCombie and Thirlwall's assertions). For example, Clavijo and Ros (2015, p. 25) state that 'conventional estimates of [Thirlwall's] law are estimating that in the long run the growth rates of imports and exports should be more or less the same'. Nevertheless, when one reads Clavijo and Ros's argument more carefully, one finds that it really requires a second assumption, which - as I shall explain below - is equivalent to the first condition stated above.

The two steps in the near-tautology critique are somewhat easier to discern in the analysis of Razmi (2016), who discusses how econometric estimates of the income elasticities are likely (under certain assumptions) to satisfy equations (3) and (4), in which case 'the traditional approach to testing the BPCG model is really a test of whether or not exports and imports grow at similar rates' (ibid., p. 1585). Although Razmi implies that this 'test' only applies if it is found (separately) that (3) or (4) is satisfied, his presentation rather blends these two steps in the argument together, which could lead to confusion. ${ }^{9}$ In what follows, I will try to make the two steps

9. Razmi essentially substitutes the equivalent of equations (7) and (8) below into the equivalent of (1) and (2), while simultaneously imposing the assumption that $\bar{g}_{Q}=0$. 
that are implicit in Razmi's (2016) analysis more explicit, while using McCombie's (2019) distinction between the 'estimated' and 'calculated' elasticities to help clarify the issues at stake. I will present the argument in terms of the strong version of Thirlwall's law in equation (2), but the same logic applies to the weak version in equation (1).

Standard constant-elasticity demand functions for exports and imports, written in growth-rate form, are as follows (ignoring lags for expositional simplicity):

$$
\begin{gathered}
g_{X, t}=\alpha_{X}+\varepsilon_{X} g_{Q, t}+\eta_{X} g_{Y, t}^{f}+e_{t} \\
g_{M, t}=\alpha_{M}-\varepsilon_{M} g_{Q, t}+\eta_{M} g_{Y, t}+u_{t},
\end{gathered}
$$

where a subscript $t$ indicates the time period, $\alpha_{X}$ and $\alpha_{M}$ are constants, $Q=E P^{f} / P$ is the real exchange rate (RER) measured as the relative price of foreign goods (so a higher RER indicates a real depreciation), $E$ is the nominal exchange rate in domestic currency per unit of foreign currency, $P$ is the price level (again, an $f$ superscript indicates foreign), $g_{Q}=g_{E}+g_{P}^{f}-g_{P}$ is the rate of increase in the RER or rate of real currency depreciation, ${ }^{10} \varepsilon_{X}$ and $\varepsilon_{M}$ are relative price or RER elasticities (defined so as to be positive), ${ }^{11}$ and $e_{t}$ and $u_{t}$ are random errors (assumed to have zero means and constant variances). Since all the variables are expressed in log differences, the constants $\alpha_{X}$ and $\alpha_{M}$ represent exponential time trends, and will be zero unless such time trends are statistically significant. ${ }^{12}$ Also, the use of log differences implies that the other coefficients $\left(\varepsilon_{i}\right.$ and $\left.\eta_{i}, i=X, M\right)$ can be interpreted as elasticities. ${ }^{13}$

10. The use of this 'external' measure of the RER implicitly assumes an industrialized economy that has some power to set the price level for its traded goods (for example, because they are imperfect substitutes for foreign products). For small, dependent economies that are pricetakers, it is arguably the 'internal' exchange rate (relative price of tradeable to non-tradeable goods) that is more important to resource allocation and economic performance, since prices of tradeable goods are pinned down by foreign (world) prices. Furthermore, econometric estimates of functions like (5) and (6) for countries that do not meet the underlying assumptions could yield spurious estimates of price and income elasticities (especially for exports). See Razmi (2016) for a more general BPCG model that encompasses the small-country case as well as the Thirlwall model as special cases, and for discussion of the role of purchasing power parity in the BPCG framework.

11. In many empirical studies, separate relative prices for exported and imported goods are used instead of RERs. I use a simpler formulation in terms of the RER here since this distinction is not important for purposes of this discussion. It should also be noted that conventional measures of prices of traded goods may be problematic because of the prevalence of intra-firm pricing of goods 'traded' across national boundaries by multinational enterprises, which could bias estimates of price elasticities due to measurement error.

12. Any constant or intercept term in the underlying export and import demand functions, written in levels or log levels, would be eliminated by differencing.

13. The interpretation of the $\varepsilon_{i}$ coefficients as price elasticities of demand requires the assumption of infinitely elastic supplies, which is more likely to be true for imports than for exports especially in small countries, as discussed by Razmi (2016). Small countries are likely to be price-takers in export markets, especially for exports of primary commodities (which are typically priced in US dollars), which violates the standard BPCG assumption (similar to what is assumed in the Marshall-Lerner condition) that prices are fixed in the seller's currency. More broadly, critics of such elasticity estimates have expressed concerns about whether standard estimates of the demand functions (5) and (6) are correctly 'identified' in an econometric sense. 
If we now consider the estimated equations corresponding to (5) and (6), they can be written as:

$$
\begin{gathered}
\hat{g}_{X, t}=\hat{\alpha}_{X}+\hat{\varepsilon}_{X} g_{Q, t}+\hat{\eta}_{X} g_{Y, t}^{f} \\
\hat{g}_{M, t}=\hat{\alpha}_{M}-\hat{\varepsilon}_{M} g_{Q, t}+\hat{\eta}_{M} g_{Y, t},
\end{gathered}
$$

where $\hat{g}_{X, t}$ and $\hat{g}_{M, t}$ are the fitted values of the dependent variables and $\hat{\varepsilon}_{X}, \hat{\varepsilon}_{M}, \hat{\eta}_{X}$ and $\hat{\eta}_{M}$ are the estimated coefficients. Adding up each of these equations across all time periods in the sample and dividing by the number of observations, $\left(5^{\prime}\right)$ and $\left(6^{\prime}\right)$ can be solved for the estimated income elasticities in relation to the sample means of the variables:

$$
\begin{gathered}
\hat{\eta}_{X}=\frac{\bar{g}_{X}-\hat{\alpha}_{X}-\hat{\varepsilon}_{X} \bar{g}_{Q}}{\bar{g}_{Y}^{f}} \\
\hat{\eta}_{M}=\frac{\bar{g}_{M}-\hat{\alpha}_{M}+\hat{\varepsilon}_{M} \bar{g}_{Q}}{\bar{g}_{Y}},
\end{gathered}
$$

where we use the fact that the means of the fitted values of the dependent variables must equal the sample means of their actual values (since the mean of the estimated residuals must be zero).

Now, we can clearly see the conditions for equtions (3) and (4) to hold or not hold. Essentially, equations (3) and (4) are likely to hold (as approximations) if the constants (time trends) are insignificant (so that $\hat{\alpha}_{X} \approx 0$ and $\hat{\alpha}_{M} \approx 0$ ) and if the relative price or RER effect is negligible - either because the estimated price/RER elasticities are insignificant so that $\hat{\varepsilon}_{X} \approx 0$ and $\hat{\varepsilon}_{M} \approx 0$ or else because the relative price does not change (RER is constant) in the long run so that $\bar{g}_{Q} \approx 0$. But of course, the assumption that relative price effects are negligible is one of the foundational pillars of Thirlwall's law. Either of the same two alternative conditions (insignificant price elasticities or a constant RER in the long run) can be invoked to derive equation (1), while only the latter condition implies equation (2).

Indeed, McCombie (2011, p. 358, emphasis in the original) has written that 'a continuous [real] depreciation of the currency ... is implausible' in the long run. ${ }^{14}$ Thus, McCombie supports the assumption that $\bar{g}_{Q} \approx 0$, and if in addition $\hat{\alpha}_{X}$ and $\hat{\alpha}_{M}$ are small and/or insignificant (as they are likely to be, if exports and imports do not exhibit underlying trends that are independent of the effects of national incomes and relative prices), then the estimated income elasticities will approximate the calculated elasticities $\bar{\eta}_{X}$ and $\bar{\eta}_{M}$ as shown in equations (3) and (4). If this is true, and if (in addition) $X$ and $M$ grow at similar rates in the long run, then the estimated BP-equilibrium growth rate $\hat{g}_{Y}^{B}=\hat{\eta}_{X} \bar{g}_{Y}^{f} / \hat{\eta}_{M}$ will necessarily be close to the actual sample mean growth rate, $\bar{g}_{Y}$.

However, it is important to emphasize that this conclusion will not hold if the estimated constants (time trends) are quantitatively non-negligible and statistically

14. It should be noted that the assumption of no continuous change in the RER in the long run does not rule out the possibility of a shift in the long-run average level of the RER. Several empirical studies have found statistically significant positive effects of RER undervaluation (in levels) on longrun growth (for example, Rodrik 2008; Rapetti et al. 2012; Razmi 2016), although this evidence has been contested by others including Professor McCombie and co-authors (for example, in Ribeiro et al. 2020). 
significant, or if the price (RER) elasticities are statistically significant and the rate of change in the relative price (RER) does not have a zero mean $\left(\bar{g}_{Q} \neq 0\right)$, or if any other independent variables are included in the export and import demand functions and are statistically significant with non-zero means. If any of these conditions are met, then equations (3) and (4) will not hold and the near-tautology critique will not apply. Thus, the near-tautology critique is only relevant in cases where no other variables besides the income growth rates (domestic and foreign) matter to import and export demand in the long run, either because those other variables have statistically insignificant coefficients or because their growth rates have zero means.

Now we are in a position to see how the argument of Clavijo and Ros (2015) really requires the same two separate conditions. Clavijo and Ros frame their analysis in terms of the weak version of Thirlwall's law in equation (1). Assuming that relative prices (RERs) are constant in the long run (as McCombie and Thirlwall have long maintained), so that $g_{Q}=0$, and also implicitly assuming no exponential time trend in the underlying import demand function (so that $\alpha_{M}=0$ ), and suppressing time subscripts and the error term for simplicity, the import demand function (6) becomes

$$
g_{M}=\eta_{M} g_{Y}
$$

which is in fact how import demand has been specified in several theoretical extensions of the BPCG model (for example, Palley 2002; Setterfield 2006; Oreiro 2016). Then, substituting equation $\left(6^{\prime \prime}\right)$ into (1), we find that

$$
g_{Y}^{B}=\frac{g_{X}}{g_{M}} g_{Y},
$$

where Thirlwall's law will appear to hold (approximately) as long as $g_{X} \approx g_{M}$ (measured by sample means). However, it is clear that equation (6") applies only under the same conditions that are required, as argued above, for the econometrically estimated income elasticity of imports to approximate the calculated one $\left(\hat{\eta}_{M} \approx \bar{\eta}_{M}\right)-$ especially, $g_{Q}=0$. Thus, it is implicit in Clavijo and Ros's presentation that $\hat{\eta} \approx \bar{\eta}_{M}$ and $g_{X} \approx g_{M}$ are logically two separate conditions; the latter does not imply the former, and the latter by itself is not sufficient to imply $\bar{g}_{Y}=g_{Y}^{B}$.

Nevertheless, McCombie $(2011 ; 2019)$ and Thirlwall $(1981 ; 2019)$ are correct in saying that, as long as the relative price (RER) term is included in the regression equations, the estimated income elasticities will incorporate the behaviour of the relative prices (RER) as well as the income variables. Consider an ordinary least squares (OLS) linear regression with two independent variables,

$$
W_{t}=b_{0}+b_{1} Z_{1 t}+b_{2} Z_{2 t}+v_{t},
$$

where $W$ is the dependent variable, the $Z_{i}(i=1,2)$ are the independent variables, ${ }^{15}$ the $b_{j}$ are the coefficients, and $v$ is the error term (with $\bar{v}=0$ and constant $\sigma_{v}^{2}$ ). The estimated coefficient (elasticity) for the $Z_{2}$ variable is ${ }^{16}$

15. I use this somewhat unusual notation for the regression equation instead of the more standard $Y$ and $X$ to avoid confusion with the macroeconomic meanings of these letters (income and exports, respectively).

16. Adapted from Michael T. Brannick, 'Regression with two independent variables', available at: http://faculty.cas.usf.edu/mbrannick/regression/Part3/Reg2.html (accessed 22 December 2019). 


$$
\widehat{b}_{2}=\frac{\left(\sum z_{1}^{2}\right)\left(\sum z_{2} w\right)-\left(\sum z_{1} z_{2}\right)\left(\sum z_{1} w\right)}{\left(\sum z_{1}^{2}\right)\left(\sum z_{2}^{2}\right)-\left(\sum z_{1} z_{2}\right)^{2}},
$$

where $w=W-\bar{W}$ and $z_{i}=Z_{i}-\bar{Z}_{i}$ are the differences of the variables from their sample means. Supposing, for example, that equation (9) represents the import function (6), then the dependent variable $W$ is $g_{M}, Z_{1}$ is the rate of change in the RER $\left(g_{Q}\right)$ and $Z_{2}$ is the income growth rate $\left(g_{Y}\right)$, and the estimated coefficient on $g_{Y}$ (income elasticity) $\widehat{b}_{2}=\hat{\eta}_{M}$ depends on the observations for relative price (RER) changes $Z_{1}=g_{Q}$.

Clearly, equation (10) is not the same as simply the ratio of the sample mean growth rates in equation (4), and therefore does not necessarily approximate the 'calculated' elasticity, $\bar{W} / \bar{Z}_{2}=\bar{g}_{M} / \bar{g}_{Y}=\bar{\eta}_{M}$. Moreover, they are not generally the same even if the estimated coefficient $\widehat{b}_{1}$ is insignificant or if the $Z_{1}$ variable (RER change) has a zero mean. Also, if additional variables are included in the regression equation, then $\hat{b}_{2}=\hat{\eta}_{M}$ will depend on the values of those other variables as well as income and the RER. Nevertheless, it can be seen through empirical simulations (available on request) that if the deviations of the changes in the RER from their mean are small, so that $z_{1}$ is clustered around zero, then $g_{Q}$ will have only a small influence on the estimated $\hat{b}_{2}=\hat{\eta}_{M}$ and the fitted values $\hat{W}=\hat{g}_{M}$ will be closely approximated by $\hat{b}_{2} Z_{2}=\hat{\eta}_{M} g_{Y} \cdot{ }^{17}$

So, what should we believe? On the one hand, Razmi (2016) argues (and I concur) that the estimated income elasticities will approximate the calculated ones under the conditions outlined above in relation to equations (7) and (8), that is, when all right-hand-side variables in the export and import demand functions other than the income variables have either insignificant coefficients or (approximately) zero means (with the variables measured in growth rate form). On the other hand, McCombie and Thirlwall argue that there is no reason to expect econometrically estimated elasticities to approximate the calculated ones, regardless of whether relative price (RER) effects are significant or whether relative prices (RERs) are stationary in the long run. In the end, McCombie (2019) is absolutely correct in one respect: this is an empirical question. The next section provides some empirical evidence about whether (or under what circumstances) the near-tautology critique is applicable, using data for two major countries.

\section{EMPIRICAL EVIDENCE FOR THE US AND MEXICAN ECONOMIES}

Although he states (correctly) that the near-tautology argument is an empirical question, McCombie (2019) offers only a 'simulation exercise' in lieu of actual data analysis. For this purpose, he constructs five hypothetical databases - with ten 'annual observations' 18 - in each of which he imposes the assumption that $\bar{g}_{X}=\bar{g}_{M}$, in other words, exports and imports grow at exactly the same rate on average. He then runs a set of regressions, both with and without relative prices (presumably, also simulated ones) included, to obtain the estimated income elasticities, and finds that the

17. I am indebted to Arslan Razmi for suggesting this point.

18. McCombie (2019, p. 433, n. 4) states that using longer samples of 20 or 30 'years' would not affect his results. 
latter often differ (in some cases very substantially) from the 'calculated elasticities', which (by construction of the hypothetical data series) both always equal 2.0. He then claims that this refutes what he calls 'Blecker's tautology'.

However, McCombie misstates the near-tautology critique that he purports to be refuting. He claims that, 'according to Blecker, inter alios, this relationship [that the average growth rates of exports and imports are exactly equal] is all that is necessary to ensure that Thirlwall's law is a tautology' (ibid., p. 433, italics in the original). That is not what I said, and although their presentations may be less clear on the matter, I think it is also not an accurate reflection of the arguments in Clavijo and Ros (2015) or Razmi (2016) (especially the latter) for the reasons stated in the previous section. As discussed above, the critique is logically a doubly conditional one: if the estimated income elasticities $\hat{\eta}_{X}$ and $\hat{\eta}_{M}$ approximate the calculated elasticities $\bar{\eta}_{X}$ and $\bar{\eta}_{M}$ (respectively), and if (this is a separate condition) the growth rates of exports and imports are similar, then Thirlwall's law will appear to hold (again, approximately). The second of these conditions (exports and imports grow at similar rates) is not 'all that is necessary' for the estimated $\hat{g}_{Y}^{B}$ to be close to the actual sample mean $\bar{g}_{Y}$, and whatever one might infer from some statements in the previous literature, I certainly did not say that.

Rather than engage in more simulation exercises, I will instead rely on actual data for two countries whose economies I have studied extensively: the US and Mexico. For this purpose, I utilize data sets that I (and various co-authors) have constructed for two other research projects. The first of these is the US data set used in Blecker et al. (2020); the second is the Mexican data set used by Ibarra and Blecker (2016). Thus, these data were not cherry-picked for use in writing this reply - and in fact, as will be seen below, the near-tautology critique is validated for only one of the two countries. Of course, these could be special cases: the US is the world's largest advanced economy and relatively closed, while Mexico is a highly open emerging economy whose exports are intensive in intermediate imports and very dependent on the US market. However, it is also possible that these two countries could be representative of advanced and emerging economies, respectively. ${ }^{19}$ In fact, McCombie (2004) has argued that the BPCG model and its predecessor, the Harrod (1933) trade multiplier, do apply to large countries like the US even though trade is a relatively small share of their output. Hence, the US data should provide a fair empirical test of the near-tautology argument. In any event, the data for these two countries reveal very neatly why, from a statistical point of view, the near-tautology view holds in one case (the US) but not the other (Mexico). To what extent either case is representative of other countries would have to be the subject of future research; these two are used here strictly for illustrative purposes.

For the US case, I ran regressions of the general form shown in equations (5) and (6), with lag lengths selected by the Schwarz criterion to avoid injecting any personal judgment into the lag selection. ${ }^{20}$ The estimated export and import demand functions, using

19. Indeed, the US and Mexico are representative of one important feature of global trade, that is 'North-South' trade between advanced and emerging or developing economies. Several studies have extended the BPCG framework to address North-South trade, including Dutt (2002) and Cimoli and Porcile (2014), among many others. A full discussion of this literature would be beyond the scope of the present article.

20. The only exception is that the Schwarz criterion calls for including the lagged dependent variable in the import equation, but that variable has a coefficient that is very small and statistically insignificant, so it was omitted. 
annual data from Blecker et al. (2020) for the sample period 1963-2016 (the same period used in that paper), are shown in Table 1. Since all variables are measured in log differences, the coefficients can be interpreted as elasticities. The 'long-run' coefficients in the export equation are the sums of all included lags ( 0 to 1 ) divided by one minus the coefficient on the lagged dependent variable, while in the import equation they are simply the sums of the coefficients on all included lags ( 0 up to 2 ) of each independent variable (because there is no lagged dependent variable in the latter equation - when it is included, it has a very small and insignificant coefficient). Both equations fit the data reasonably well, with an adjusted $R^{2}$ around 0.7 , for data measured in $\log$ differences. Moreover, both equations pass four diagnostic tests for statistically

Table 1 Estimated demand functions for US exports and imports of goods and services, annual data for 1963-2016, all variables measured in first differences of natural logarithms

\begin{tabular}{|c|c|c|}
\hline Dependent variable & Exports $_{t}$ & Imports $_{t}$ \\
\hline Exports $_{t-1}$ & $\begin{array}{l}0.580^{* * *} \\
(0.101)\end{array}$ & $\begin{array}{l}- \\
-\end{array}$ \\
\hline Real exchange rate ${ }_{t}$ & $\begin{array}{l}-0.445^{* * * *} \\
(0.085)\end{array}$ & $\begin{array}{c}0.044 \\
(0.108)\end{array}$ \\
\hline Real exchange rate rel $_{t-1}$ & - & $\begin{array}{c}0.123 \\
(0.121)\end{array}$ \\
\hline Real exchange rate ${ }_{t-2}$ & $\begin{array}{l}- \\
-\end{array}$ & $\begin{array}{l}0.157 \\
(0.122)\end{array}$ \\
\hline Foreign income $_{t}$ & $\begin{array}{l}2.431 * * * \\
(0.254)\end{array}$ & - \\
\hline Foreign income $_{t-1}$ & $\begin{array}{l}-1.690 * * * \\
(0.348)\end{array}$ & - \\
\hline Domestic income $_{t}$ & - & $\begin{array}{l}2.543 * * * \\
(0.217)\end{array}$ \\
\hline Domestic income $_{t-1}$ & - & $\begin{array}{c}-0.107 \\
(0.250)\end{array}$ \\
\hline Domestic income $_{t-2}$ & $\begin{array}{l}- \\
- \\
\end{array}$ & $\begin{array}{l}-0.534 * * \\
(0.215) \\
\end{array}$ \\
\hline Long-run RER elasticity & $\begin{array}{l}-1.059 * * * \\
(0.328)\end{array}$ & $\begin{array}{l}0.324 * * \\
(0.140)\end{array}$ \\
\hline Long-run income elasticity & $\begin{array}{l}1.763 * * * \\
(0.280)\end{array}$ & $\begin{array}{l}1.901 * * * \\
(0.136)\end{array}$ \\
\hline $\begin{array}{l}\text { Adjusted } R^{2} \\
\quad \text {-values for diagnostic tests: }\end{array}$ & 0.692 & 0.737 \\
\hline Breusch-Godfrey serial correlation & 0.157 & 0.181 \\
\hline Jarque-Bera normality & 0.874 & 0.693 \\
\hline Breusch-Pagan-Godfrey heteroscedasticity & 0.254 & 0.529 \\
\hline Ramsey RESET misspecification & 0.588 & 0.481 \\
\hline
\end{tabular}

Notes: Estimated using an ARDL specification in OLS, with lags selected by the Schwartz criterion using a maximum of 2 lags, except the lagged dependent variable was omitted from the import equation because its coefficient was very small and insignificant, and the negative sign made the calculation of the long-run coefficient (elasticity) dubious. The real effective exchange-rate index from Darvas (2012), last updated 4 October 2019, is an index of the real value of the dollar, and hence is the reciprocal of the theoretical real exchange rate $Q$ in the text (so its coefficients are expected to have the opposite signs). Standard errors in parentheses (significance levels: $* 10$ per cent, $* * 5$ per cent, $* * * 1$ per cent). 
valid estimates at the 10 per cent level: Breusch-Godfrey tests show no significant serial correlation of the residuals; Jarque-Bera tests show that the null hypothesis of normality of the residuals cannot be rejected; Breusch-Pagan-Godfrey tests show no heteroscedasticity of the residuals; and Ramsey RESET tests show no evidence of equation misspecification. The estimated long-run price (RER) elasticities are statistically significant at the 1 per cent level for exports and the 5 per cent level for imports, while the estimated long-run income elasticities are both significant at the 1 per cent level. All of the estimated long-run coefficients (elasticities) have the expected signs (note that the empirical RER index for the US is measured as the real value of the dollar, so these signs are the reverse of what were shown in equations (5) and (6) above).

Table 2 then compares the estimated (long-run) income elasticities from the regressions in Table 1 with the calculated income elasticities (ratios of sample means of the variable in log differences). As can be seen, these two types of elasticities are in fact very similar: for exports, the estimated income elasticity $\hat{\eta}_{X}=1.76$ in line (7) is very close to the calculated elasticity $\bar{\eta}_{X}=1.85$ in line (6); for imports, the estimated income elasticity $\hat{\eta}_{M}=1.90$ in line (9) is almost exactly the same as the calculated elasticity $\bar{\eta}_{M}=1.87$ in line (8). As a result, the estimated and calculated BP-equilibrium growth rates are very close to each other and to the actual average growth rate - even more so using the weak version of Thirlwall's law (which requires only the income elasticity of imports), but also using the strong version (which also includes the income elasticity of exports). Actual US growth averaged 2.96 per cent per year during the 1963-2016 period, just slightly higher than the BP-equilibrium growth rates of 2.92 (calculated) and 2.73 (estimated) using the strong version of Thirlwall's law (lines (10)-(11) in Table 2), and 2.92 (calculated) and 2.87 (estimated) using the weak version (lines (12)-(13)).

Table 2 Calculated and estimated income elasticities, BP-equilibrium growth rates, and other relevant growth rates, based on annual US data for 1963-2016

(1) Mean growth rate of domestic income, $\bar{g}_{Y}$

(2) Mean growth rate of foreign income, $\bar{g}_{Y}^{f}$

(3) Mean growth rate of exports, $\bar{g}_{X}$

(4) Mean growth rate of imports, $\bar{g}_{M}$

(5) Mean rate of change in the RER index, $-\bar{g}_{Q}=\bar{g}_{P}-\bar{g}_{E}-\bar{g}_{P}^{f}$

$-0.03$

(6) Calculated income elasticity for exports, $\bar{\eta}_{X}=(3) /(2)$

(7) Estimated income elasticity for exports, $\hat{\eta}_{X}$

(8) Calculated income elasticity for imports, $\bar{\eta}_{M}=(4) /(1)$

(9) Estimated income elasticity for imports, $\hat{\eta}_{M}$

(10) Calculated BP-equilibrium growth rate, strong version, $\bar{g}_{Y}^{B}=(6) \times(2) /(8)$

(11) Estimated BP-equilibrium growth rate, strong version, $\hat{g}_{Y}^{B}=(7) \times(2) /(9)$

(12) Calculated BP-equilibrium growth rate, weak version, $\bar{g}_{Y}^{B}=(3) /(8)$

(13) Estimated BP-equilibrium growth rate, weak version, $\hat{g}_{Y}^{B}=(3) /(9)$

Notes: Growth rates are measured by differences in natural logarithms, expressed in per cent per year. The RER index used in these regressions measures the reciprocal of the RER used in the equations in the text (it is the relative cost of US goods, instead of the relative cost of foreign goods); hence the rate of change (log difference) is the negative of the rate of change in the theoretical $Q$. Estimated elasticities are the long-run coefficients from Table 1. 
The interesting question is why the US data so closely conform to the near-tautology argument. One key reason, which can be seen in line (5) of Table 2, is that - even though the RER elasticities of export and import demand are statistically significant the long-run average rate of change in the US RER index is virtually zero. Furthermore, constants were not included in the estimated equations; there are no significant time trends for US exports or imports, once the appropriate income and price (RER) variables are controlled for. As a result, equations (3) and (4) hold as close approximations. In this case, Thirlwall's law must approximately hold if, in addition, the average growth rates of exports and imports are similar, which is true in this data set (both are approximately 5.5 per cent per annum). But note that the latter condition only matters since it is also true that the estimated and calculated income elasticities are very similar, contrary to what McCombie says. Otherwise - if exports and imports grew at similar rates, but the estimated income elasticities differed notably from the calculated ones - then the estimated and calculated elasticities could yield very different 'predictions' of the BP-equilibrium growth rate (as McCombie shows in some of his simulations). But at least in the US case, it seems that Clavijo and Ros (2015) and Razmi (2016) are correct: in the absence of a significant constant (time trend) and since the relative price variable (RER) has a mean rate of change close to zero, the estimated income elasticities closely approximate the calculated ones, and because (in addition) exports and imports grow at about the same rate, Thirlwall's law must appear to hold.

The Mexican case is more complicated, and some explanation is required to motivate the model I will use. In fact, Mexico has been the subject of much work in the BPCG literature. Early studies applying the BPCG model to Mexico (Moreno-Brid 1998; 1999; 2002; Pacheco-López and Thirlwall 2004; Pacheco-López 2005) generally found that the income elasticity of Mexico's import demand increased more than proportionately to the rise in export growth after the liberalization of the country's trade in the late 1980s, so that the BP-equilibrium growth rate decreased after trade liberalization. Blecker and Ibarra (2013) then modified this analysis in order to reflect the unique structural characteristics of Mexico's trade including the way in which its manufactured exports are embedded in global supply chains. ${ }^{21}$ First, they disaggregated Mexico's trade into two types of exports (manufactured and non-manufactured) and two types of imports (intermediate and final goods). ${ }^{22}$ Second, they showed the strong dependency of Mexico's intermediate imports on manufactured exports by estimating an equation with the following general specification (ignoring lags and structural breaks for simplicity here):

$$
g_{I M, t}=\alpha_{I M}-\varepsilon_{I M} g_{Q, t}+\eta_{I M} g_{Y, t}+\mu_{I M} g_{M X, t}+v_{t},
$$

21. In effect, Mexico is part of a triangular pattern of trade in which it imports capital and intermediate goods largely from Asia and Europe (although also, to some extent, from the US) and exports manufactured goods assembled using those imported inputs chiefly to the US market. It should be noted that global supply (or 'value') chains may make it more difficult for countries to eliminate BP imbalances via RER adjustment; indeed, Ibarra and Blecker (2016) found that the impact of an RER change on Mexico's BP-equilibrium growth was reduced after Mexico became more embedded in those chains and, as a result, the share of intermediate goods in its imports increased.

22. This disaggregation of imports built upon the earlier work of Ibarra (2011), who used three categories: intermediate, capital, and consumption goods. Blecker and Ibarra (2013) combined the latter two into final goods. For an alternative way of incorporating intermediate imports into a BPCG model, see Ribeiro et al. (2017a; 2017b). 
where $I M$ stands for intermediate imports, $\alpha_{I M}$ is a constant (time trend), $M X$ indicates manufactured exports, $\mu_{I M}$ is the elasticity of intermediate imports with respect to manufactured exports, ${ }^{23}$ and $v_{t}$ is a random error term. In contrast, manufactured exports and final imports were modelled in a more traditional way, similar to equations (5) and (6) above (but with dummy variables included to control for outlier observations and structural breaks). Third, Blecker and Ibarra (2013) extended the time period to 2006, which allowed for a more long-term perspective on the outcome of Mexico's trade liberalization. And fourth, in the spirit of Araujo and Lima (2007) and Gouvêa and Lima (2010), they allowed for structural change in the form of changing shares of the different types of exports and imports over time.

Applying an extended 'weak' version of the BPCG model (that is, taking the growth of both types of exports as exogenous), Blecker and Ibarra (2013) found that Mexico's BP-equilibrium growth rate actually increased in the post-liberalization period (defined as 1987-2006), compared with the earlier years in the sample (1960-1986), but actual average growth remained below the higher BP-equilibrium rate in the 1987-2006 period. Similar to Ibarra (2011), they also found that the income elasticity increased only for imports of final (consumption and capital) goods, not intermediate goods, after trade liberalization, but by the later part of their sample period the latter accounted for about three-quarters of Mexican imports. What prevented the BP-equilibrium growth rate from increasing even more post-liberalization was the rise in the share of intermediate imports, which detracted from the benefits of rapid growth of manufactured (but intermediate-import-intensive) exports.

Ibarra and Blecker (2016) developed the analysis further by endogenizing manufactured exports ${ }^{24}$ and extending the sample period to 2012. In addition, they found several structural breaks in the estimated relationships, which led them to identify five distinct sub-periods (1960-1974, 1975-1986, 1987-1993, 1994-2000 and 2001-2012) for comparing actual and BP-equilibrium growth rates in the Mexican economy. These breaks match up well with the timing of major changes in Mexico's economic structure, policy regime and external constraints. ${ }^{25}$ Ibarra and Blecker (2016) found that their earlier result for the post-liberalization period (BP-equilibrium growth increased but actual growth was slower) held only for the 1994-2000 sub-period, whereas in 2001-2012 the BP-equilibrium growth rate fell (mostly because of a slowdown in the US economy,

23. Since total output is also included in the equation, Blecker and Ibarra $(2013$, p. 42) note that 'the coefficient on [manufactured export growth] measures the effect of an increase in manufactured exports holding GDP constant, which implies a shift in the composition of total output toward the export sector. Thus, the positive coefficient on exports means that export production is more intensive in intermediate imports than the rest of the economy ...'.

24. The authors endogenized only manufactured exports in the belief that the standard approach to export demand, reflected in equation (5), is only appropriate for industrial goods. Since Mexican non-manufactured exports consist largely of agricultural products plus oil and other minerals, the authors assumed that these goods have prices that are exogenously given in US dollars by world market conditions and that the quantities exported by Mexico depend largely on domestic supply constraints (also taken as exogenous). This is an example of building structural differences between different types of exports into a modified BPCG framework.

25. The year 1975 marked the beginning of a 20-year era of macroeconomic crises and boombust cycles; 1987 was around the beginning of the process of trade liberalization; 1994 was the year when Mexico joined the North American Free Trade Agreement (NAFTA); and the post2001 period coincided with a slowdown in the growth of the US economy as well as China's accession to the World Trade Organization (which was followed by extremely rapid growth of Chinese exports to North America). 
where 80 per cent of Mexico's exports are sold, along with increased competition from China). Actual growth of about 2 per cent per annum was within the range of the estimated BP-equilibrium rates for the post-2001 sub-period.

In the following discussion, rather than running new regressions for Mexico, I will use the estimated coefficients (elasticities) and sample means from Ibarra and Blecker (2016) for the last four of these periods combined (1975-2012). The years 1960-1974 are omitted here because the econometric estimates that included that period were less precise for an era when Mexico was a relatively closed economy with strongly protectionist policies and the trade data were of poor quality, but none of the qualitative conclusions would be altered if those years were also included. ${ }^{26}$ The descriptive data for Mexico (sample mean growth rates for the 1975-2012 period, measured by log differences and expressed as percentages) are given in Table 3. Several things are clear from these data. First, Mexico's GDP grew sluggishly during this period (only about 3.1 per cent per year), in spite of very rapid growth of exports (9.0 per cent for manufactured goods and 8.2 per cent overall). Second, weighted average export growth was a full percentage point higher than weighted average import growth. This is not surprising, because Mexico went from having large current-account deficits (measured as percentages of GDP) in the late 1970s (and several subsequent periods, especially the early 1990s) to having only small deficits in the 2000s. Further interpretation of this discrepancy will be provided below. Finally, the mean rate of change in the Mexican RER (rate of real depreciation) was an order of magnitude greater than in the US case (in absolute value, 0.44 versus 0.03 per cent per year), and also somewhat more volatile (with a standard deviation of 12.9 for Mexico versus 9.7 for the US, both measured as percentage deviations in indexes based on 100 in a base year).

Table 4 shows the range of estimates of key elasticities for the 1975-2012 period from Ibarra and Blecker (2016) and compares them with the corresponding

\section{Table 3 Average growth rates for the Mexican economy, in per cent per year, based on annual data for 1975-2012}

\begin{tabular}{ll}
\hline Gross domestic product (GDP) & 3.06 \\
Manufactured exports & 9.03 \\
Non-manufactured exports & 6.27 \\
Intermediate imports & 7.93 \\
Final imports & 4.85 \\
Weighted average exports & 8.16 \\
Weighted average imports $^{-16}$ & 7.12 \\
\hline Real exchange rate (rate of change) & 0.44 \\
US GDP & 2.69
\end{tabular}

Notes: Growth rates are measured as differences in natural logarithms, expressed at annual percentage rates. Final imports are the sum of imported consumption goods and capital goods.

a. The real exchange rate is measured as the relative price of foreign goods, so a positive rate of change indicates a real depreciation of the peso.

Source: Data set used in Ibarra and Blecker (2016) and author's calculations.

26. Among other problems, manufactured exports from the maquiladora sector had to be estimated for some years prior to 1975. Also, the estimated income elasticity of demand for imports of final goods was significantly lower in the pre-1975 period, according to an interactive structural break test. Nevertheless, the earlier estimates (going back to 1960) are used in the discussion in Section 4, below, because they relate to the long-term dynamics of adjustment. 
Table 4 Alternative elasticities, calculated and estimated, for the Mexican economy, period 1975-2012

\begin{tabular}{|c|c|c|c|}
\hline & \multirow[t]{2}{*}{ Calculated } & \multicolumn{2}{|c|}{ Estimated } \\
\hline & & $\begin{array}{l}\text { Pesaran bounds } \\
\text { testing }\end{array}$ & $\begin{array}{l}\text { OLS first } \\
\text { differences }\end{array}$ \\
\hline \multicolumn{4}{|l|}{ Income elasticities: } \\
\hline Manufactured exports & 3.36 & 4.79 & 1.84 \\
\hline Final imports & 1.58 & 2.42 & 2.13 \\
\hline Intermediate imports & 2.59 & 0.52 & 0.87 \\
\hline \multicolumn{4}{|l|}{ Other elasticities: } \\
\hline $\begin{array}{l}\text { Manufactured export elasticity of } \\
\text { intermediate imports }\end{array}$ & 0.88 & 0.70 & 0.64 \\
\hline
\end{tabular}

Source: Ibarra and Blecker (2016) and author's calculations based on the underlying data set therein.

'calculated' elasticities derived from ratios of the mean growth rates from Table 3. Clearly, the calculated income elasticities are not nearly as similar to the estimated ones in the Mexican data as they are in the US data. Two of them are not far off, however. The calculated income elasticity for manufactured exports of 3.36 lies within the (admittedly wide) range of estimates of 1.84-4.79 from two alternative econometric methodologies (bounds testing, à la Pesaran et al. 2001, and OLS applied to log differences). Also, the calculated elasticity for final goods imports of 1.58 is only moderately below the lower end of the estimated range of 2.13-2.42. The calculated income elasticity for intermediate imports, in contrast, is very far off from the estimates (2.59 compared with a range of 0.52-0.87). However, as Ibarra and Blecker's estimates of equation (11) show, Mexican imports of intermediate goods are largely driven by manufactured export production, which typically transforms imported inputs into finished or semi-finished manufactured goods. As a result, the calculated elasticity of intermediate imports with respect to manufactured exports $\left(\bar{\mu}_{I M}=\bar{g}_{I M} / \bar{g}_{M X}=0.88\right)$ is very close to the corresponding estimated elasticity $\left(\hat{\mu}_{I M}\right.$, which has a range of 0.64-0.70).

Why do the Mexican data not satisfy the near-tautology critique nearly as much as the US data do? The answer has little to do with the difference in the weighted-average growth rates of exports and imports (which, after all, differ by only about 1 percentage point). Rather, the reason is that the econometric equations that Ibarra and Blecker (2016) estimated were considerably more complex than the simple functions of the types shown in equations (5) and (6), especially (but not only) for intermediate imports. These additional complexities imply that we cannot expect equations (3) and (4) to hold in the Mexican case.

First, in order to obtain statistically valid estimates using the Mexican data, Ibarra and Blecker (2016) needed to include various structural breaks and time trends, which for the reasons noted earlier, would prevent the estimated income elasticities from closely approximating the calculated ones. Specifically, their bounds-testing equation for final imports included an intercept dummy for 1987-2012, their OLS log differences model of intermediate goods required an interactive dummy for the RER for the years 1994-2012, their OLS log differences model of manufactured exports contained separate structural breaks (shifts in time trends) in 1987 and 2001 , and many of their equations required dummies for particular outlier years, in order to satisfy standard diagnostic tests for serial correlation, normality, equation 
misspecification, and heteroscedasticity. ${ }^{27}$ With all of these extra variables included, it should be expected that the estimated income elasticities would differ from the calculated ones.

Second, including the growth rate of manufactured exports as a regressor in the intermediate import demand function (11) naturally breaks the link between growth of these imports and domestic output. One would not expect intermediate imports to be closely linked to domestic output when those imports are heavily tied to export production. Using the log-difference version with a structural break included, the estimated income elasticity for intermediate imports with the variables evaluated at their sample means is

$$
\hat{\eta}_{I M}=\frac{\bar{g}_{I M}+\hat{\varepsilon}_{I M} \bar{g}_{Q}+\hat{\varepsilon}_{94-12} D_{94-12} \bar{g}_{Q}-\hat{\mu}_{I M} \bar{g}_{M X}}{\bar{g}_{Y}},
$$

where we cannot eliminate the RER effect because $\bar{g}_{Q} \neq 0$ and its coefficient is significant, $D_{94-12}$ is a dummy variable that equals one in 1994-2012 and zero otherwise (representing a statistically significant structural change in the RER effect for those years), $\hat{\varepsilon}_{94-12}$ is the estimated change in the RER coefficient in that sub-period, and again we use the fact that the estimated residuals have a mean of zero and the mean of the fitted values equals the sample mean for the dependent variable. Thus, the estimated income elasticity for Mexican imports of intermediate goods $\hat{\eta}_{I M}$ is likely to be very different from the calculated one $\left(\bar{\eta}_{I M}=\bar{g}_{I M} / \bar{g}_{Y}\right)$, as indeed we have found. Quantitatively, the main reason for this is that the term $-\hat{\mu}_{I M} \bar{g}_{M X}$ in the numerator of equation (12) is very large (and negative), which explains why we find that $\hat{\eta}_{I M} \ll \bar{\eta}_{I M}$. As a result, the near-tautology critique does not apply to the Mexican case.

Finally, Table 5 shows the alternative estimates of the BP-equilibrium growth rate for Mexico, averaged for the 1975-2012 period, using three alternative versions of the extended BPCG model in Ibarra and Blecker (2016) and two of their alternative estimation methods. ${ }^{28}$ The three different models include a weak version (all exports are exogenous), a strong version in which manufactured exports are endogenous (but the RER is assumed constant in the long run), and a more general strong version in which manufactured exports are endogenous and effects of RER changes are incorporated. The six different estimates show a relatively narrow range of about 3.4-4.0 for Mexico's BP-equilibrium growth rate. According to all of these estimates, Mexico's actual average annual growth of 3.1 per cent (shown in Table 3) was less than its BP-equilibrium growth rate during that period. ${ }^{29}$ This finding is consistent with the slower

27. Additional structural breaks, time trends, and outlier dummies had to be included (for econometric reasons) in the equations estimated for the full 1960-2012 sample by Ibarra and Blecker (2016), and many of these breaks were found in 1975 (including some structural breaks in the income elasticities themselves). This is another reason why I focus on the elasticities estimated for the 1975-2012 period in the presentation here.

28. See Appendix 1 for the equations used to compute the BP-equilibrium growth rates for Mexico. A third method, using a reduced-form equation for the trade balance, is not included here, but yields qualitatively similar results.

29. In earlier work, Blecker and Ibarra (2013) found that the actual average and BP-equilibrium growth rates were very close for Mexico for a different sample period (1960-2006), using a model with only one structural break (at the time of trade liberalization in 1987). However, they also found that the BP constraint was binding only in the pre-liberalization sub-period (1960-1986) and not the post-liberalization sub-period (1987-2006). Also the data set used in that article lacked complete data for the maquiladora sector, which were included in Ibarra and Blecker (2016). 
Table 5 Alternative estimates of the BP-equilibrium (Thirlwall's law) growth rate for Mexico, 1975-2012

\begin{tabular}{lcc}
\hline Version & $\begin{array}{c}\text { Pesaran bounds } \\
\text { testing }\end{array}$ & $\begin{array}{c}\text { OLS first } \\
\text { differences }\end{array}$ \\
\hline Weak (manufactured exports exogenous) & 3.63 & 3.41 \\
Strong (manufactured exports endogenous) & 3.81 & 3.48 \\
Strong (manufactured exports endogenous) with RER effects & 3.98 & 3.77 \\
\hline
\end{tabular}

Notes: See Appendix 1 for the equations used to calculate the BP-equilibrium (Thirlwall's law) growth rates. The growth rate of non-manufactured exports was treated as exogenous in all estimates. What are reported here are the averages for four different sub-periods in the original article (1975-1986, 1987-1993, 1994-2000, and 2001-2012), weighted by the number of years in each sub-period.

Source: Ibarra and Blecker (2016) and author's calculations.

growth of Mexico's imports compared with its exports noted earlier, since the slow growth of domestic demand would be likely to hold down the growth of imports relative to exports.

If one takes all of these estimates at face value, they seem to imply that Thirlwall's law holds closely for the US economy but does not hold for Mexico. However, the near-tautology critique fits the US case like a glove, since the estimated elasticities are very close to the calculated ones and exports and imports grew at almost identical rates, whereas the estimated elasticities differ much more from the calculated ones in the Mexican case, so the near-tautology critique does not apply to the latter. If one takes the Mexican estimates literally, they appear to imply that other constraints besides the BP - for example, the contractionary fiscal and monetary policies frequently adopted in the interest of macroeconomic 'stabilization' (or possibly the supply-side obstacles and institutional deficiencies emphasized by some Neoclassical authors $)^{30}$ - were more binding constraints on the Mexican economy on average over the entire 37-year period from 1975 to 2012. So, does this mean that Thirlwall's law does not apply in Mexico? I will argue in the next section that Thirlwall's law does indeed apply to Mexico in the long run, while the US case is more uncertain because the near-tautology critique applies to the US estimates.

\section{RETHINKING THE BALANCE-OF-PAYMENTS CONSTRAINT AND MORE POWERFUL EMPIRICAL TESTS}

Fortunately, there is another way of thinking about the BPCG model that suggests a more powerful approach to empirical testing of Thirlwall's law. ${ }^{31}$ As noted earlier, McCombie and Thirlwall have both stressed the importance of national income, rather than relative prices or the RER, being the adjusting variable for achieving BP equilibrium in the long run as the key foundation of Thirlwall's law:

$[R]$ lative price changes combined with the price elasticity of demand for imports (and exports [in the strong version of the model]) are not an efficient balance of payments

30. See Blecker (2021) on the debate about the causes of Mexico's economic stagnation (where I argue that a tightening of the BP constraint after 2001 is an important part of the story). 31. The following discussion draws upon portions of Blecker (2016) and Blecker and Setterfield (2019, pp. 475-476). 
adjustment weapon. It is income growth that adjusts to equilibrate the balance of payments. (McCombie and Thirlwall 2004, introduction, p. 11)

Pérez Caldentey (2015) - while defending Thirlwall's law against the criticisms of Clavijo and Ros (2015) - has restated this point very clearly. Pérez Caldentey points out that similar long-run average growth rates of exports and imports - which we have seen are a critical, but only partial, aspect of the near-tautology critique - are actually a key ingredient in Thirlwall's law. But he says that identifying the mechanism that establishes equilibrium between those growth rates constitutes the 'essential idea' of Thirlwall's law, which 'establishes that it is through variations in the level (or growth rate) of income, not by an adjustment in relative prices, that an equilibrium between $x$ and $m$ is achieved' (Pérez Caldentey 2015, p. 58 - where $x$ and $m$ are the growth rates of exports and imports, respectively).

Citing various econometric difficulties with the conventional empirical approach, Alonso and Garcimartín (1998-1999, pp. 266 and 276) argued that Thirlwall's law 'cannot be tested through the degree of correlation between [the] actual and Thirlwall's Law rate[s] of growth'. Instead, they sought to explicitly 'test the balance-of-payments constraint hypothesis by identifying the variable by means of which the balance-ofpayments equilibrium is achieved'. Alonso and Garcimartín (1998-1999) then provided an alternative econometric methodology for conducting such a test. They tested the two alternative hypotheses (income adjustment versus relative price adjustment) for ten industrialized countries, using a simultaneous equations framework to control for the endogeneity of exports and imports. For each country, they compared the results of two alternative models: one estimating the income growth response to BP disequilibria (trade imbalances) and one estimating the relative price response, while including in each model the same equations for export and import demand (thus making exports and imports endogenous in the income or price adjustment equation).

Alonso and Garcimartín (ibid.) found that the income adjustment mechanism was statistically significant and had the right sign (income grows more rapidly in response to a rising trade surplus, or more slowly in response to a widening deficit) in eight of the ten countries considered; in contrast, the price adjustment mechanism was statistically insignificant for all countries studied. Interestingly, the US was one of the two exceptions in which income adjustment was also insignificant (the other one was France), suggesting that the apparent 'success' of the BPCG model in explaining US growth (as shown in Table 2) could be a result of the near-tautology phenomenon. However, their sample period was limited to 1965-1994, and to the best of my knowledge no one has replicated or updated Alonso and Garcimartín's study for a large sample of countries in the past two decades. ${ }^{32}$

Additional evidence about income versus price adjustment comes from studies that have applied cointegration methods to test the BPCG hypothesis, beginning with Moreno-Brid (1999; 2002) on Mexico and Pérez Caldentey and Moreno-Brid (1999) on Central America. Cointegration methods allow the identification of longrun relationships in time-series data that are integrated of the same order (usually the data series have unit roots) while controlling for short-run adjustments or 'error corrections'. In a study of India, Razmi (2005, p. 682) found that 'income was by far the dominant influence in determining the balance-of-payments constraint in the

32. However, Garcimartín et al. (2010-2011) applied an extended version of the Alonso and Garcimartín (1998-1999) model incorporating relative prices, net transfers and capital flows to data for Spain and Portugal in the period 1975-2007 and found statistically significant adjustment of income growth in response to current-account imbalances in these two countries. 
long run' using the weak form of Thirlwall's law, but relative price effects were sometimes important in the short run and results for the strong form were more mixed and depended on the time period. Razmi (2005, p. 668) also found that when price variables were significant in cointegrating vectors for India, they sometimes adjusted 'in the "wrong" - that is, disequilibrating - direction'. Lima and Carvalho (2008) found that national income and exports are significantly cointegrated with each other but not with the RER, using annual time-series data for 1930-2004 in Brazil.

More recently, Felipe et al. (2019) develop an innovative approach to testing for the adjustment of income to a BP constraint. First, they use a Kalman filter to estimate time-varying income elasticities for Indonesia's imports and exports, which in turn are used to construct time-varying estimates of the BP-equilibrium growth rate in equation (2), the strong version of Thirlwall's law. Then, Felipe et al. (2019, pp. 548-549) define a variable that measures the difference between the actual and (time-varying) BP-equilibrium growth rates, ydiff $f_{t} g_{Y, t}-g_{Y, t}^{B}$, and another one that measures whether 'a country's growth rate relative to the world's trend growth rate will reflect the ratio of the export to the import income elasticities', $y$ diff $t$ $\left(g_{Y, t} / g_{Y, t}^{f, T}\right)-\left(\hat{\eta}_{X, t} / \hat{\eta}_{M, t}\right)$ (where $t$ subscripts have been added to variables that are time-varying and a $T$ superscript indicates the long-run trend value derived from a Hodrick-Prescott filter). ${ }^{33}$

The authors then test whether these two difference variables are (i) stationary, mean-reverting processes and (ii) zero-mean processes. Using unit-root tests for hypothesis (i) and an autoregressive regression model for (ii), Felipe et al. (2019) find that both conditions are met in the Indonesian data. Notably, this approach goes beyond testing for whether actual growth tends to equal the BP-equilibrium rate (which is confirmed by the tests of (ii)) to also show that divergences between the two rates do not persist and the former adjusts to the latter (as implied by the evidence for (i)) - although the calculated half-lives of the deviations are around five years, indicating 'that deviations from the long-run equilibrium are very persistent' (ibid., p. 550). I consider that this approach is very much in the spirit of testing for the significance of an income-adjustment mechanism, as advocated here.

McCombie and Thirlwall (2004, introduction, p. 14) have cited the work of Alonso and Garcimartín (1998-1999) approvingly, as a complement to more conventional tests of Thirlwall's law. However, I believe that the Alonso-Garcimartín approach really suggests a fundamental reorientation of how we think about testing the BPCG model: instead of directly testing the model's prediction about the long-run average growth rate, we should rather test for the adjustment mechanism that maintains BP equilibrium in the long run. In this reconceptualization, the BP-equilibrium growth rate (Thirlwall's law) becomes a benchmark for an analysis of this adjustment process: if a national economy tends to grow faster than its BP-equilibrium rate for some period of time, then its growth should subsequently slow down, and such income adjustment - rather than

33. The authors' use of a Hodrick-Prescott filter to identify the trend suggests one note of caution about their results, given the demonstration in Hamilton (2018, abstract, p. 831) that '(a) The Hodrick-Prescott (HP) filter introduces spurious dynamic relations that have no basis in the underlying data-generating process. (b) Filtered values at the end of the sample are very different from those in the middle and are also characterized by spurious dynamics'. This is especially troublesome because Felipe et al. (2019) find differences in the income elasticities (especially for exports) at the end of their sample compared with the earlier part. Hence, using an alternative method of measuring the trend, such as the one suggested by Hamilton (2018), would be an important sensitivity test for their results. 
relative price or RER adjustment - should be the main way that BP equilibrium is restored in the long run (while allowing that a currency devaluation could possibly be an additional adjustment tool in the short run). In this view, whether the actual and BP-equilibrium growth rates are nearly equal over any given period of time is less important than whether deviations between them lead to equilibrating responses of output growth rates rather than exchange rates or relative prices, again in the long run.

In fact, some of the recent work of Professor McCombie - especially the 'grand synthesis' model of Ribeiro et al. (2017a) - may be interpreted as consistent with such a view. This model does not imply that countries always grow at the long-run, Thirlwall's law growth rate over any given historical period. On the contrary, the model analyses the circumstances that can lead countries to grow at different rates still compatible with BP equilibrium - over short- and medium-run horizons. Unless those short- and medium-run growth rates happen to vary symmetrically around the long-run BP-equilibrium rate, there is no reason to expect that average growth over any given period (from a few years to even a few decades) will necessarily coincide with the long-run Thirlwall's law rate. What the model does imply, however, is that over a long enough period (and absent other shocks or structural changes), output growth will eventually converge to that rate. ${ }^{34}$

This alternative way of thinking about Thirlwall's law explains why I believe that it does help to account for the Mexican experience, in spite of the fact that Mexico's long-run average growth rate is less than its estimated BP-equilibrium rate. To show how the model applies to the Mexican long run, Table 6 compares the actual average growth rates for Mexico with the range of estimates for the various sub-periods in Ibarra and Blecker (2016), where the sub-periods were determined by structural breaks in the underlying equations (export and/or import demand functions, as described in the previous section). ${ }^{35}$ As Table 6 shows, the Mexican economy grew faster than its BP-equilibrium rate during the 1960-1974 sub-period. The result was rising current-account deficits in the early to mid 1970s, which led a series of BP crises, each of which was marked by a sharp currency devaluation in the short run and persistently slower growth over longer periods of time. In the next sub-period (1975-1986), which included three such crises, actual average growth was lower than in the previous period and at the lower end of the corresponding range of estimated BP-equilibrium rates. We can see the impact of the BP constraint in the way that the macroeconomic 'stabilization policies' adopted during the aftermath of the 1982-1983 debt crisis restored BP equilibrium but only at the cost of a severe economic slowdown.

In the following sub-period (1987-1993), actual growth slowed down further, but exceeded the BP-equilibrium growth rate only because the latter declined even more (especially in the estimates that incorporate the impact of the real appreciation of the peso during that sub-period). Again, the current-account deficit mushroomed as growth exceeded the BP-constrained rate. The next sub-period (1994-2000) corresponds to the early years of NAFTA, which went into effect in 1994, and also the peso ('tequila') crisis of 1994-1995, which occurred in response to the large current-account deficit and related

34. Interestingly, the model does require adjustments in unit labour costs to achieve that convergence, such that the real wage grows at the same rate as labour productivity and the wage share is constant in the long-run equilibrium.

35. For this purpose, I will refer to the results for the entire period 1960-2012 covered by Ibarra and Blecker (2016), because their results for the early years (1960-1974) are important to the story I want to tell (even though, from a statistical point of view, the estimates for those years were less precise). 
Table 6 Actual average growth rates and estimated BP-equilibrium growth rates for Mexico, selected periods, 1960-2012

\begin{tabular}{lcc}
\hline & \multicolumn{2}{c}{ Growth rates (per cent per year) } \\
\hline & Actual average & BP-equilibrium (range of estimates) \\
\hline Whole sample: $1960-2012$ & 4.0 & 4.1 to 5.1 \\
Sub-samples: & & \\
1960-1974 & 6.3 & 2.0 to 4.4 \\
1975-1986 & 3.9 & 3.7 to 6.4 \\
$1987-1993$ & 3.1 & -0.1 to 2.9 \\
$1994-2000$ & 3.5 & 6.1 to 7.6 \\
$2001-2012$ & 2.0 & 1.7 to 2.8 \\
\hline
\end{tabular}

Note: a. Estimates using the authors' trade-balance model are omitted because they were anomalously high or low in a few sub-periods.

Source: Ibarra and Blecker (2016).

financial meltdown, as well as the subsequent recovery. In the 1994-2000 period, average growth picked up slightly (to 3.5 per cent, from 3.1 per cent in the previous sub-period), but was now below the range of estimates for the BP-equilibrium growth rate as the latter increased notably. Once again, contractionary 'stabilization' policies prevented the Mexican economy from achieving the growth rate made possible by the BP constraint. Finally, in 2001-2012, Mexico's (very low) average annual growth rate of 2.0 per cent per year was within the range of 1.7 to 2.8 for the estimated BP-equilibrium rate for that period. Consistent with these estimates, the Mexican current account exhibited only very small and stable deficits (as a percentage of GDP) during that period. This slow growth (which has continued since 2012) has spawned a wide-ranging debate over the causes of Mexican stagnation, but as I have argued elsewhere (see Blecker 2021), to me it indicates that the BP constraint did eventually bind the Mexican economy in the historical long run. ${ }^{36}$

The Mexican case also teaches something else: in an economy undergoing rapid structural change, the BP-equilibrium growth rate is a constantly changing target. That's another reason to be more concerned with the adjustment process than with 'predicting' the long-run average growth rate. Furthermore, the Mexican example shows that these adjustments may take place over several decades and through a series of crises and responses, so they may not necessarily be visible in standard annual timeseries data. In any case, the best way to see the applicability of the BPCG model to Mexico is not by comparing its actual average growth rate with the estimated BP-equilibrium growth rate for the whole long-run sample, but rather by examining the longrun dynamics and policy shifts that eventually led the country to adjust the former

36. For other applications of Thirlwall's law to emerging-market countries that take structural breaks (or 'growth transitions') into account, see Tharnpanich and McCombie (2013) and Mhlongo and Nell (2019) on Thailand and South Africa, respectively. The latter study finds that South Africa had chronic current-account deficits (financed by net capital inflows) in periods when its actual growth exceeded the BP-equilibrium rate. Mhlongo and Nell also find that in the most recent sub-period in their sample (2004-2017), growth slowed down (converged toward the BP-equilibrium rate) in the later part of the period in response to large deficits earlier in the period. Mhlongo and Nell thus use the BP-equilibrium growth rate as a benchmark for predicting current-account deficits and subsequent adjustments of income growth, similarly to how it is used in Ibarra and Blecker (2016). 
growth rate to the latter (with the two rates coinciding only in the most recent period, which was one of renewed stability but very slow growth). In contrast, Thirlwall's law seems to hold almost exactly for the US economy, but this could be a statistical fluke due to the applicability of the near-tautology critique to the US estimates, while the results of Alonso and Garcimartín (1998-1999) suggest that US national income did not adjust in the way contemplated by the BPCG model at least during their sample period (1965-1994).

\section{CONCLUSIONS AND THE WAY FORWARD}

Progress in economic analysis (heterodox, Post-Keynesian or otherwise) requires that models and theories are open to rigorous debate - and such debate can only be fruitful if criticisms accurately reflect the views of those being criticized. McCombie (2019) and Thirlwall (2019) mischaracterized my arguments in Blecker (2016) in at least three respects. First, I did not say that Thirlwall's law or the BPCG model was a theoretical tautology; I only discussed the likelihood that some empirical tests of that law could be testing a near-tautology under certain conditions. Second, I did not claim that the income elasticities typically used in computing the BP-equilibrium growth rate are measured by ratios of growth rates of exports and foreign income or imports and domestic income; I merely considered whether econometrically estimated income elasticities might sometimes approximate the elasticities calculated by such ratios. And third, I did not claim that approximate equality of the growth rates of exports and imports is sufficient for the estimated income elasticities to approximate the calculated ones; although this may not have been sufficiently clear in the previous literature, these are two logically separate and independent conditions that both need to hold for the near-tautology critique to apply. If I had said any of those things, my arguments could be dismissed as inaccurate or illogical, but I did not make such fallacious claims. Hence, the criticisms of McCombie and Thirlwall miss the mark.

In this article, I have argued that the near-tautology problem will arise whenever these two conditions hold: first, the econometrically estimated income elasticities are close to the descriptive or 'calculated' ones (which will occur if RER effects are negligible, there are no significant time trends, and no other variables except relative prices and incomes are included in the export and import demand functions); and second, the growth rates of exports and imports are similar on average in the long run. Although most participants in this debate agree that the second condition is likely to hold in most countries, there is much more disagreement about how often the first condition is satisfied. Clearly, this is an empirical question that can only be settled by further research on more countries, but the estimates discussed here show that the first condition holds in the US data but not in Mexican data, precisely because the latter do not satisfy the first condition. It seems plausible that the US is not an isolated case, assuming that the first condition is likely to be satisfied in other advanced economies where RERs don't change much in the long run and there are no structural shifts or time trends to take into account, but of course this remains to be tested in future research. It also seems plausible that Mexico could be similar to other emerging nations whose trade is embedded in global supply chains and which have undergone profound structural changes and policy shifts, but that too would have to be verified in future research.

Nevertheless, apart from this disagreement about empirical methods, it is important to emphasize the much broader areas of agreement between Professors McCombie and Thirlwall and myself. As emphasized above, Thirlwall's law is not a theoretical 
tautology because it can be (and has been) tested by alternative empirical methodologies that assess whether income (rather than relative prices) adjusts to eliminate current-account imbalances (or, equivalently, deviations of actual from BP-equilibrium growth). Thirlwall's original, core idea that the BP constraint can impose a demandside limit on the long-run growth of open economies is one that I fully accept and agree with. The development of the BPCG model since 1979 has rightly focused attention on external constraints on the growth process, an idea that was at the core of early, Structuralist development economics, but which has been abandoned by mainstream, Neoclassical development economists since the 1970s with their emphasis on supplyside factors and micro-level behaviour. Indeed (and here I completely agree with Thirlwall 2019), the 'potential' output growth rate emphasized in Neoclassical growth models is endogenous and adjusts to the actual, average long-run growth rate when the latter is BP-constrained or otherwise demand-determined (see Lanzafame 2014, among others).

On the empirical side, I believe that estimates of the Thirlwall's law or BP-equilibrium growth rate are important benchmarks for determining whether national incomes or relative prices are the main adjusting variables in response to BP disequilibria (in the long run). My argument is that direct tests of this adjustment process provide much stronger validation of the BPCG approach than the more conventional empirical tests of equality between actual average and estimated BP-equilibrium growth rates, the latter of which may be subject to the near-tautology critique under the conditions outlined above. Ultimately, verification of the adjustment mechanism hypothesized in Thirlwall's law, rather than ex post 'prediction' of actual average growth performance, seems to me a more fruitful empirical approach. The fact that tests of this adjustment process validate it for most but not all countries, as in Alonso and Garcimartín (1998-1999), suggests that they have more power to reject the null hypothesis of income adjustment in cases where this hypothesis is actually false compared with standard tests of Thirlwall's law. In contrast, the standard approach will tend to confirm that the law holds in cases where the near-tautology critique applies, regardless of which variable actually adjusts (income, prices or something else).

There are still many more issues about the BPCG approach that are subject to lively debate, as discussed in Blecker (2016) and Blecker and Setterfield (2019) as well as McCombie (2011) and Thirlwall (2011). What kinds of extensions or modifications to the original Thirlwall framework are necessary or important for modelling countries with different kinds of economic structures? Are exports always constrained only by foreign demand, or can domestic supply constraints sometimes be important, and in that case how should the BP constraint be modelled? Does only non-price competitiveness matter in the long run (and for all countries), or can relative prices and RERs also affect long-run BP constraints, and if so how? As noted earlier, some economists have argued that levels of relative prices or RERs can have long-run effects even if continuous changes in these variables are implausible in the long run (for example, Razmi 2016), ${ }^{37}$ a view that is

37. In some models, these level effects operate by altering the structural composition, and hence the weighted-average income elasticities, of exports and/or imports, which in turn can impact upon the catch-up of developing countries toward advanced economies (see, among many others, Cimoli and Porcile 2014; Oreiro 2016). These models are based on the premise that an undervalued level of the RER can affect the supply side of the economy by diverting resources from non-tradeables and low return activities to tradeables and increasing return activities, as has occurred historically in several East Asian economies (see also Frenkel and Ros 2006; Rodrik 2008; Ros 2015). 
contested by others (for example, Ribeiro et al. 2016; 2017b; 2020). Future progress in the BPCG framework and Post-Keynesian/Structuralist analysis of external constraints to growth more broadly depends on taking these complexities into account in both theoretical models and empirical estimates.

\section{REFERENCES}

Alonso, J. and C. Garcimartín (1998-1999), 'A new approach to the balance-of-payments constraint: some empirical evidence', Journal of Post Keynesian Economics, 21(2), 259-282.

Araujo, R.A. and G.T. Lima (2007), 'A structural economic dynamics approach to balance-ofpayments-constrained growth', Cambridge Journal of Economics, 31(5), 755-774.

Blecker, R.A. (1992), 'Structural roots of U.S. trade problems: income elasticities, secular trends, and hysteresis', Journal of Post Keynesian Economics, 14(3), 321-346.

Blecker, R.A. (1998), 'International competition, relative wages, and the balance-of-payments constraint', Journal of Post Keynesian Economics, 20(4), 495-526.

Blecker, R.A. (2002), 'The balance-of-payments-constrained growth model and the limits to export-led growth', in P. Davidson (ed.), A Post Keynesian Perspective on Twenty-First Century Economic Problems, Cheltenham, UK and Northampton, MA: Edward Elgar Publishing, pp. 69-88.

Blecker, R.A. (2013), 'Long-run growth in open economies: export-led cumulative causation or a balance-of-payments constraint?', in G.C. Harcourt and P. Kriesler (eds), The Oxford Handbook of Post-Keynesian Economics, vol. I, Theory and Origins, Oxford: Oxford University Press, pp. 390-414.

Blecker, R.A. (2016), 'The debate over "Thirlwall's law": balance-of-payments-constrained growth reconsidered', European Journal of Economics and Economic Policy: Intervention, 13(3), 275-290.

Blecker, R.A. (2018), 'Interview with Robert A. Blecker: "people will come searching for us postKeynesians if the political atmosphere is encouraging", by Eckhard Hein and Marc Lavoie, European Journal of Economics and Economic Policy: Intervention, 15(3), 250-258.

Blecker, R.A. (2021), 'Mexico: unequal integration and "stabilizing stagnation"', in L.R. Wray and F. Dantas (eds), Handbook of Economic Stagnation, Amsterdam: Elsevier, forthcoming.

Blecker, R.A. and C.A. Ibarra (2013), 'Trade liberalization and the balance of payments constraint with intermediate imports: the case of Mexico revisited', Structural Change and Economic Dynamics, 25(June), 33-47.

Blecker, R.A. and A. Razmi (2008), 'The fallacy of composition and contractionary devaluations: output effects of real exchange rate shocks in semi-industrialised countries', Cambridge Journal of Economics, 32(1), 83-109.

Blecker, R.A. and A. Razmi (2010), 'Developing country exports of manufactures: moving up the ladder to escape the fallacy of composition', Journal of Development Studies, 44(1), 21-48.

Blecker, R.A. and M. Setterfield (2019), Heterodox Macroeconomics: Models of Demand, Distribution and Growth, Cheltenham, UK and Northampton, MA: Edward Elgar Publishing.

Blecker, R.A., M. Cauvel and Y. Kim (2020), 'Systems estimation of a structural model of distribution and demand in the U.S. economy', FMM Working Paper No 54, June.

Cimoli, M. and G. Porcile (2014), 'Technology, structural change and BOP-constrained growth: a structuralist toolbox', Cambridge Journal of Economics, 38(1), 215-237.

Clavijo, P.H. and J. Ros (2015), 'La ley de Thirlwall: una lectura crítica', Investigación Económica, 74(292), 11-40.

Darvas, Z. (2012), 'Real effective exchange rates for 178 countries: a new database', Working Paper 2012/06, Bruegel, available at: https://bruegel.org/publications/datasets/real-effectiveexchange-rates-for-178-countries-a-new-database/ (last updated 4 October 2019).

Dutt, A.K. (2002), 'Thirlwall's law and uneven development', Journal of Post Keynesian Economics, 24(3), 367-390. 
Felipe, J., M. Lanzafame and G. Estrada (2019), 'Is Indonesia's growth rate balance-of-payments-constrained? A time-varying estimation approach', Review of Keynesian Economics, 7(4), 537-553.

Frenkel, R. and J. Ros (2006), 'Unemployment and the real exchange rate in Latin America', World Development, 34(4), 631-646.

Garcimartín, C., L.A. Rivas and P. García Martínez (2010-2011), 'On the role of relative prices and capital flows in balance-of-payments-constrained growth: the experiences of Portugal and Spain in the euro area', Journal of Post Keynesian Economics, 33(2), 281-306.

Gouvêa, R.R. and G.T. Lima (2010), 'Structural change, balance-of-payments constraint, and economic growth: evidence from the multisectoral Thirlwall's law', Journal of Post Keynesian Economics, 33(1), 169-204.

Guschanski, A. and E. Stockhammer (2020), 'Are current accounts driven by cost competitiveness or asset prices? A synthetic model and an empirical test', Cambridge Journal of Economics, advance access, published online, 22 June.

Hamilton, J.D. (2018), 'Why you should never use the Hodrick-Prescott filter', Review of Economics and Statistics, 100(5), 831-843.

Harrod, R. (1933), International Economics, London: Macmillan.

Houthakker, H.S. and S.P. Magee (1969), 'Income and price elasticities in world trade', Review of Economics and Statistics, 51(2), 111-125.

Ibarra, C.A. (2011), 'A note on intermediate imports and the BPCG model in Mexico', Economic Change and Restructuring, 44, 357-368.

Ibarra, C.A. and R.A. Blecker (2016), 'Structural change, the real exchange rate and the balance of payments in Mexico, 1960-2012', Cambridge Journal of Economics, 40(2), 507-539.

Lanzafame, M. (2014), 'The balance of payments constrained growth rate and the natural rate of growth: new evidence', Cambridge Journal of Economics, 38(4), 817-838.

Lima, G.T. and V.R. Carvalho (2008), 'Macrodinâmica do produto sob restrição externa: a experiência brasilera no período 1930-2004', Economia Aplicada, 12(1), 55-77.

McCombie, J.S.L. (1981), 'Are international growth rates constrained by the balance of payments? A comment on professor Thirlwall', Banca Nazionale del Lavoro Quarterly Review, (139), 455-458.

McCombie, J.S.L. (2004), 'Economic growth, the Harrod foreign trade multiplier and the Hicks super-multiplier', in J.S.L. McCombie and A.P. Thirlwall (eds), Essays on Balance of Payments Constrained Growth: Theory and Evidence, London: Routledge, pp. 40-57.

McCombie, J.S.L. (2011), 'Criticisms and defences of the balance-of-payments constrained growth model: some old, some new', PSL Quarterly Review, 64(259), 353-392.

McCombie, J.S.L. (2019), 'Why Thirlwall's law is not a tautology: more on the debate over the law', Review of Keynesian Economics, 7(4), 429-443.

McCombie, J.S.L. and A.P. Thirlwall (1994), Economic Growth and the Balance-of-Payments Constraint, New York: St. Martin's.

McCombie, J.S.L. and A.P. Thirlwall (eds) (2004), Essays on Balance of Payments Constrained Growth: Theory and Evidence, London: Routledge.

Mhlongo, E. and K.S. Nell (2019), 'Growth transitions and the balance-of-payments constraint', Review of Keynesian Economics, 7(4), 498-516.

Moreno-Brid, J.C. (1998), 'Balance-of-payments constrained economic growth: the case of Mexico', Banca Nazionale del Lavoro Quarterly Review, 207, 413-433.

Moreno-Brid, J.C. (1998-1999), 'On capital flows and the balance-of-payments-constrained growth model', Journal of Post Keynesian Economics, 21(2), 283-298.

Moreno-Brid, J.C. (1999), 'Mexico's economic growth and the balance of payments constraint: a cointegration analysis', International Review of Applied Economics, 13, 149-159.

Moreno-Brid, J.C. (2002), 'Liberalización comercial y la demanda de importaciones en México', Investigación Económica, 62, 13-51.

Oreiro, J.L. (2016), 'Inconsistency and over-determination in balance-of-payments-constrained growth models: a note', Review of Keynesian Economics, 4(2), 193-200.

Pacheco-López, P. (2005), 'The impact of trade liberalization on exports, imports, the balance of trade, and growth: the case of Mexico', Journal of Post Keynesian Economics, 27, 595-619. 
Pacheco-López, P. and A.P. Thirlwall (2004), 'Trade liberalisation in Mexico: rhetoric and reality', Banca Nazionale del Lavoro Quarterly Review, (229), 141-167.

Palley, T.I. (2002), 'Pitfalls in the theory of growth: an application to the balance-of-paymentsconstrained growth model', in M. Setterfield (ed.), The Economics of Demand-Led Growth: Challenging the Supply-Side Vision of the Long Run, Cheltenham, UK and Northampton, MA: Edward Elgar Publishing, pp. 115-125.

Pérez Caldentey, E. (2015), 'Una lectura crítica de la "lectura crítica" de la Ley de Thirlwall', Investigación Económica, 74(292), 47-65.

Pérez Caldentey, E. and J.C. Moreno-Brid (1999), 'Terms of trade, exports and economic growth in Central America: a long-term view', Banca Nazionale del Lavoro Quarterly Review, 52(211), 431-449.

Perraton, J. (2003), 'Balance of payments constrained growth and developing countries: an examination of Thirlwall's hypothesis', International Review of Applied Economics, 17(1), 1-22.

Pesaran, M.H., Y. Shin and R.J. Smith (2001), 'Bounds testing approaches to the analysis of level relationships', Journal of Applied Econometrics, 16, 289-326.

Rapetti, M., P. Skott and A. Razmi (2012), 'The real exchange rate and economic growth: are developing countries different?', International Review of Applied Economics, 26(6), 735-753.

Razmi, A. (2005), 'Balance-of-payments-constrained growth model: the case of India', Journal of Post Keynesian Economics, 27(4), 655-687.

Razmi, A. (2016), 'Correctly analysing the balance-of-payments constraint on growth', Cambridge Journal of Economics, 40(6), 1581-1608.

Ribeiro, R.S.M., J.S.L. McCombie and G.T. Lima (2016), 'Exchange rate, income distribution and technical change in a balance-of-payments constrained growth model', Review of Political Economy, 28(4), 545-565.

Ribeiro, R.S.M., J.S.L. McCombie and G.T. Lima (2017a), 'A reconciliation proposal of demanddriven growth models in open economies', Journal of Economic Studies, 44(2), 226-244.

Ribeiro, R.S.M., J.S.L. McCombie and G.T. Lima (2017b), 'Some unpleasant currency-devaluation arithmetic in a post Keynesian macromodel', Journal of Post Keynesian Economics, 40(2), $145-167$.

Ribeiro, R.S.M., J.S.L. McCombie and G.T. Lima (2020), 'Does real exchange rate undervaluation really promote economic growth', Structural Change and Economic Dynamics, 52, 408-417.

Rodrik, D. (2008), 'The real exchange rate and economic growth', Brookings Papers on Economic Activity, 2008(2), 365-412.

Ros, J. (2015), Development Macroeconomics in Latin America and Mexico: Essays on Monetary, Exchange Rate, and Fiscal Policies, New York: Palgrave Macmillan.

Setterfield, M. (2006), 'Thirlwall's law and Palley's pitfalls: a reconsideration', in P. Arestis, J. McCombie and R. Vickerman (eds), Growth and Economic Development: Essays in Honour of A.P. Thirlwall, Cheltenham, UK and Northampton, MA: Edward Elgar Publishing, pp. $47-59$.

Tharnpanich, N. and J.S.L. McCombie (2013), 'Balance-of-payments constrained growth, structural change, and the Thai economy', Journal of Post Keynesian Economics, 35(4), 569-597.

Thirlwall, A.P. (1979), 'The balance of payments constraint as an explanation of international growth rate differences', Banca Nazionale del Lavoro Quarterly Review, (128), March, 45-53.

Thirlwall, A.P. (1981), 'A reply to Mr McCombie', Banca Nazionale del Lavoro Quarterly Review, 34(139), 458-459.

Thirlwall, A.P. (2011), 'Balance of payments constrained growth models: history and overview', PSL Quarterly Review, 64(259), 307-351.

Thirlwall, A.P. (2019), 'Thoughts on balance-of-payments constrained growth after 40 years', Review of Keynesian Economics, 7(4), 554-567.

Thirlwall, A.P. and M.N. Hussain (1982), 'The balance of payments constraint, capital flows and growth rate differences between developing countries', Oxford Economic Papers, 34(3), 498-510.

Vernengo, M. (2015), 'Una lectura crítica de la crítica al modelo de Thirlwall', Investigación Económica, 74(292), 67-80. 


\section{APPENDIX 1}

The equations used to compute the estimated BP-equilibrium growth rates for Mexico in Blecker and Ibarra (2013) and Ibarra and Blecker (2016) are as follows, translated into the notation used here. The most general 'strong' form of the equation, including RER effects, is:

$$
\begin{gathered}
\left(\varphi-\hat{\mu}_{I M} \theta\right)\left(\hat{\eta}_{M X} \bar{g}_{Y}^{f}+\hat{\alpha}_{M X}\right)+(1-\varphi)\left(\bar{g}_{T O T}+\bar{g}_{N X}\right) \\
g_{Y}^{B}=\frac{+\left[\left(\varphi-\hat{\mu}_{I M} \theta\right) \hat{\varepsilon}_{M X}+\theta \hat{\varepsilon}_{I M}+(1-\theta) \hat{\varepsilon}_{F M}-\varphi\right] \bar{g}_{Q}}{\theta \hat{\eta}_{I M}+(1-\theta) \hat{\eta}_{F M}},
\end{gathered}
$$

where $\varphi$ is the share of manufactures in total exports, $\theta$ is the share of intermediate goods in total imports (both evaluated at their sample means for the period or sub-period considered), the subscript $N X$ means non-manufactured exports (primary products), $F M$ indicates imports of final goods, TOT signifies the terms of trade for non-manufactured exports, and all other variables are defined as in the text above. Non-manufactured exports and their terms of trade are always treated as exogenously given. As before, a circumflex $\left(^{\wedge}\right)$ over a variable indicates an estimated parameter (elasticity) while an overbar $\left(^{-}\right)$indicates the sample (or sub-sample) mean of a growth rate. A time trend $\left(\hat{\alpha}_{M X}\right)$ is included for manufactured exports (for certain sub-periods) but not for either type of imports, because it was never significant in the estimated equations for the latter. Structural breaks are not included here for simplicity, but are included in the calculations where relevant.

Excluding RER effects (assuming $g_{Q}=0$ ), but still treating manufactured exports as endogenous, this equation simplifies to:

$$
g_{Y}^{B}=\frac{\left(\varphi-\hat{\mu}_{I M} \theta\right)\left(\hat{\eta}_{M X} \bar{g}_{Y}^{f}+\hat{\alpha}_{M X}\right)+(1-\varphi)\left(\bar{g}_{T O T}+\bar{g}_{N X}\right)}{\theta \hat{\eta}_{I M}+(1-\theta) \hat{\eta}_{F M}} .
$$

Finally, if manufactured exports are treated as exogenous and relative price effects are again excluded, we get the 'weak' version of Thirlwall's law for this model:

$$
g_{Y}^{B}=\frac{\left(\varphi-\hat{\mu}_{I M} \theta\right) \bar{g}_{M X}+(1-\varphi)\left(\bar{g}_{T O T}+\bar{g}_{N X}\right)}{\theta \hat{\eta}_{I M}+(1-\theta) \hat{\eta}_{F M}},
$$

which is essentially the ratio of the weighted average growth rate of exports to the weighted average income elasticity of import demand, where the numerator is adjusted for the effect of manufactured exports on intermediate imports. All of these expressions can be seen as special cases of the BPCG model with structural change, or 'multisectoral Thirlwall's law', of Araujo and Lima (2007) and Gouvêa and Lima (2010), with two exported goods and two types of imports, where one of the latter is intermediate goods used in export production. 